\title{
Caracterização de genótipos e estimativa de parâmetros genéticos de características produtivas de sorgo forrageiro ${ }^{1}$
}

\author{
Elizângela Emídio Cunha², João Maria Pinheiro de Lima³
}

\author{
1 Pesquisa financiada pelo $B N B$ \\ 2 Departamento de Genética, CB - UFRN, Natal, RN. \\ ${ }^{3}$ EMBRAPA/EMPARN, Natal, RN.
}

RESUMO - Avaliou-se o desempenho produtivo de 29 genótipos de sorgo forrageiro por meio dos dados de matéria verde, matéria seca, altura da planta, floração inicial e sobrevivência da planta. Além do desempenho, foram estimadas a herdabilidade de cada característica e as correlações genotípicas e fenotípicas entre elas, as quais são úteis nos programas de melhoramento genético empregando-se seleções direta e indireta. Utilizou-se o delineamento em blocos completos ao acaso com três repetições, em análise de variância univariada. Houve variabilidade genética para todas as características, com diferenças significativas entre as médias dos genótipos. A herdabilidade foi elevada, sobretudo para altura da planta. As correlações genotípica e fenotípica da matéria verde com a matéria seca $(0,83$ e 0,76 , respectivamente) e da matéria seca com a altura da planta $(0,87$ e 0,72) foram expressivas. As correlações foram medianas entre matéria verde e altura da planta $(0,61$ e 0,52$)$ e entre matéria verde com a sobrevivência $(0,71$ e 0,61$)$. A floração inicial foi a característica menos correlacionada às demais. A altura da planta, por ser medida antes do corte e ter apresentado herdabilidade muito alta, além de correlação genotípica moderada com a matéria verde e alta com a matéria seca, ambas medidas após o corte, pode ser utilizada para obtenção de ganho genético nessas características via seleção indireta.

Palavras-chave: alimentação animal, forragem, melhoramento genético vegetal, seleção

\section{Characterization of genotypes and estimates of genetic parameters of productive traits for forage sorghum}

\begin{abstract}
Productive performance of 29 genotypes of forage sorghum was evaluated by data of fresh matter, dry matter, plant height, initial flowering and plant survival. Heritability was also estimated for each trait, as well as the genotypic and phenotypic correlations among them. Such parameters are useful in genetic breeding programs by using direct and indirect selection. Randomized complete block design with three replications was used, in univariate analysis of variance. Genetic variability for all traits was observed and the genotype means were significantly different. Heritability presented high values, mainly for plant height. Genotypic and phenotypic correlations between fresh matter and dry matter $(0.83$ and 0.76 , respectively) and dry matter with plant height $(0.87$ and 0.72$)$ produced high values. Correlations were moderate among fresh matter and plant height (0.61 and 0.52) and among fresh matter with survival (0.71 and 0.61). Initial flowering was the trait less strongly correlated with the others. Because plant height was recorded before cutting and for showing high heritability and moderate genotypic correlation with fresh matter and a high one with dry matter, both of them observed after cutting, it appears to be feasible as to achieve genetic breeding for those traits through indirect selection.
\end{abstract}

Key Words: animal food, forage, plant genetic breeding, selection

\section{Introdução}

A cultura do sorgo (Sorghum bicolor (L.) Moench) tem potencial para ser utilizada na alimentação de animais, sobretudo nas regiões semi-áridas do Nordeste brasileiro, por ser resistente à seca e a altas temperaturas e por apresentar elevada produtividade (Oliveira et al., 2002; Pitombeira et al., 2002).
Vários cultivares de sorgo forrageiro têm sido desenvolvidos e utilizados na forma de silagem e grãos, bem como no pastejo direto pelos animais, visto que a produção de forragem de qualidade é uma necessidade premente nos sistemas intensivos de produção (Silva et al., 2005a). Neste contexto, Neumann et al. (2002a) afirmaram que o sorgo é uma planta adaptada ao processo de ensilagem e que possui características fenotípicas que determinam facilidade de plantio, manejo, colheita e armazenamento. 
O Rio Grande do Norte, com uma área física de 92\% dentro do Polígono das Secas, já foi o maior produtor de sorgo do Nordeste (Lima, 1993). No entanto, Mariguele \& Silva (2002) relataram que no estado não existem entidades produtoras de sementes da maioria das culturas, inclusive do sorgo, o que leva os agricultores a plantar grãos ou sementes de cultivares provenientes de outras regiões do país, sem avaliação nas condições locais. A principal consequência disso, segundo os autores, é que em algumas ocasiões, ocorre perda total da cultura, pelo cultivo de cultivares totalmente não-adaptados.

No sorgo forrageiro, características agronômicas como a produção de matérias verde e seca, a altura da planta e a sobrevivência, são importantes na discriminação dos genótipos promissores e, assim, podem ser úteis nos programas de melhoramento genético da cultura. Neste caso, é preciso conhecer os parâmetros genéticos relativos a essas características e suas correlações, uma vez que o conhecimento da associação genética entre elas é de grande relevância, principalmente quando a seleção em uma característica apresenta dificuldades, em razão da baixa herdabilidade e, ou, apresenta problemas de medição e identificação (Cruz et al., 2004).

Este trabalho foi realizado com os objetivos de avaliar o desempenho produtivo de genótipos de sorgo forrageiro em algumas características agronômicas e estimar os parâmetros genéticos para essas características.

\section{Material e Métodos}

O experimento foi realizado no período de abril a agosto de 2006 na Estação Experimental Gruta do Bode, pertencente à Empresa de Pesquisa Agropecuária do Rio Grande do Norte (EMPARN), localizada em Canguaretama, Rio Grande do Norte, com altitude média de $5 \mathrm{~m}$ e clima tropical quente e úmido, com médias de $21-33^{\circ} \mathrm{C}$ e pluviosidade média mensal de $170,2 \mathrm{~mm}$ no período estudado. O solo, classificado como latossolo de textura arenosa/média, de boa fertilidade, apresentou pH de 6,33; 5,0 mg/kg de P disponível; 1,3 cmolc/kg de $\mathrm{Ca}^{+2}$; CTC de 3,49 cmolc/kg e V de $57,08 \%$ na camada de 0 a $20 \mathrm{~cm}$ de profundidade. A adubação química foi feita com NPK na cova e 2/3 de nitrogênio na adubação de cobertura 25 dias após o plantio.

Foram avaliados 29 genótipos de sorgo forrageiro, dos quais 28 eram oriundos do IPA/PE (Empresa Pernambucana de Pesquisa Agropecuária) e um (BRS Ponta Negra), da EMPARN, em delineamento experimental em blocos completos ao acaso com três repetições. Cada parcela foi constituída de quatro fileiras de $6 \mathrm{~m}$ de comprimento, espaçadas $0,80 \mathrm{~m}$ entre si, considerando área útil as duas fileiras centrais no total de $9,60 \mathrm{~m}^{2}$.

Para a característica floração inicial, foi anotado o número de dias do plantio até que pelo menos $50 \%$ das plantas de cada parcela tivessem sua panícula floral totalmente desenvolvida. Antecedendo o corte, mediu-se a altura de cinco plantas tomadas ao acaso de cada parcela, calculando-se a média, e procedeu-se também à contagem da população de plantas para a análise de estande. A produção de matéria verde foi obtida pelo corte das plantas inteiras (caule, folhas e panículas) da área útil de cada parcela. A produção de matéria seca foi avaliada após a colheita da planta inteira, que foi pesada e mantida em estufa a $65^{\circ} \mathrm{C}$ durante 48 horas. Colheitas manuais foram realizadas aos 86 dias em $60 \%$ das plantas e aos 94 dias, respeitando o prazo para que as sementes das panículas atingissem o estado pastoso. A sobrevivência foi obtida a partir da relação estande final (número de plantas na parcela por ocasião da colheita)/estande inicial (número de plantas na parcela após o desbaste).

Foram feitas análises estatísticas univariadas, incluindo a média, os efeitos de tratamento (genótipos), de blocos e o erro aleatório associado a cada observação. A comparação entre as médias dos genótipos em cada característica foi feita por meio do critério de Scott-Knott a 5\% de significância. A variância fenotípica foi obtida pela divisão do quadrado médio de genótipos pelo número de blocos; a genotípica, pela diferença entre quadrado médio de genótipos e quadrado médio de resíduo dividida pelo número de blocos; e a ambiental, pelo quadrado médio de resíduo dividido pelo número de blocos.

Estimaram-se a herdabilidade para seleção com base na média dos genótipos, que foi obtida pela divisão entre as variâncias genotípica e fenotípica e, também, a correlação intraclasse pela divisão da variância genotípica pela soma do quadrado médio do resíduo com a variância genotípica (Cruz et al., 2004). Além disso, estimaram-se as correlações genotípicas e fenotípicas entre as características avaliadas, nos diferentes genótipos, por meio do programa computacional GENES (Cruz, 2001). A significância das correlações foi avaliada pelo teste t a 5\% de probabilidade.

\section{Resultados e Discussão}

Foi constatada diferença significativa $(\mathrm{P}<0,01$; teste $\mathrm{F})$ entre os genótipos para cada característica avaliada, o que indica a existência de variabilidade entre suas médias. O coeficiente de determinação $\left(\mathrm{r}^{2}\right)$ do modelo foi satisfatório para todas as características e variou de 57 a 94\%, com o 
percentual mais baixo para a floração inicial e o mais alto para a altura da planta. Pelos valores do coeficiente de variação experimental ( $\mathrm{CV}_{\mathrm{E}}$ entre 5,91 e 27,24\%), houve moderada precisão do experimento, mesmo para a matéria seca, que teve o maior índice. O menor coeficiente foi observado para altura da planta.

Por ser uma planta sensível ao fotoperíodo, o sorgo tem desenvolvimento variável, conforme a região de cultivo e a época de semeadura, o que resulta em variação no rendimento de forragem dentro e entre materiais distintos (Silva et al., 2005b).

A alta produção de matéria verde e de matéria seca e o elevado percentual de sobrevivência (Tabela 1) dos genótipos de sorgo avaliados justificam a utilização deste material como gramínea na alimentação de animais, sobretudo de ruminantes como verificado por Nascimento et al. (2008) e Igarasi et al. (2008).

A produção média de matéria verde foi de $46.777 \mathrm{~kg} / \mathrm{ha}$. Dezoito genótipos destacaram-se como os mais produtivos, com média de 45.333 a $68.100 \mathrm{~kg} / \mathrm{ha}$, seguidos de oito genótipos com produção intermediária (média de 39.133 a 44.067 kg/ha) e pelos genótipos T34 (SUDAN 4202 R1);
38-Ca84-B2Ca87-B2SB88-BCa89 e IPA 10-11, que tiveram as médias mais baixas (31.333; 27.967 e $15.400 \mathrm{~kg} / \mathrm{ha}$, respectivamente). Entre os genótipos mais produtivos, 80Ca84-01Ca87-B1SB88-BCa89; 02-03-01 e IPA 467-4-2 foram os três de maior média (68.100; 66.567 e $62.300 \mathrm{~kg} / \mathrm{ha}$, respectivamente). Silva et al. (2005b) observaram rendimentos de matéria verde variando de 24.062 a $49.333 \mathrm{~kg} / \mathrm{ha}$ em dez cultivares de sorgo forrageiro plantados em Coimbra, Minas Gerais, na primeira quinzena de outubro a maio do ano agrícola 1999/2000. Em Goiânia, Goiás, Oliveira et al. (2005) registraram matéria verde variando de 45.870 a $65.560 \mathrm{~kg} / \mathrm{ha}$ (média de $59.310 \mathrm{~kg} / \mathrm{ha}$ ) em quatro cultivares de sorgo forrageiro plantados em dezembro de 2002. No litoral do Rio Grande do Norte, Aguiar et al. (2006) não encontraram diferença significativa $(\mathrm{P}>0,05)$ entre a produção média de matéria verde dos sorgos forrageiros SF-25 (47.890 kg/ha) e IPA 467-4-2 (44.770 kg/ha) cultivados de junho a agosto de 2002. O rendimento, neste estudo, do sorgo SF-25 foi similar ao descrito por esses autores, enquanto o do IPA 467-4-2 foi consideravelmente maior.

Na avaliação da produção de matéria seca (média de $15.703 \mathrm{~kg} / \mathrm{ha}$ ), 23 genótipos revelaram-se os mais

Tabela 1 - Desempenho médio dos 29 genótipos de sorgo forrageiro para cada característica

\begin{tabular}{|c|c|c|c|c|c|}
\hline Genótipo & $\begin{array}{c}\text { Matéria } \\
\text { verde (kg/ha) }\end{array}$ & $\begin{array}{c}\text { Matéria } \\
\text { seca }(\mathrm{kg} / \mathrm{ha})\end{array}$ & $\begin{array}{l}\text { Altura da } \\
\text { planta }(\mathrm{m})\end{array}$ & $\begin{array}{l}\text { Floração } \\
\text { inicial (dias) }\end{array}$ & $\begin{array}{c}\text { Sobrevivência } \\
(\%)\end{array}$ \\
\hline 80Ca84-01Ca87-B1SB88-BCa89 & $68.100 \mathrm{~A}$ & $20.800 \mathrm{~A}$ & $3,83 \mathrm{~A}$ & $74,33 \mathrm{~A}$ & $96,73 \mathrm{~A}$ \\
\hline $02-03-01$ & $66.567 \mathrm{~A}$ & $26.100 \mathrm{~A}$ & $3,34 \mathrm{~B}$ & $75,00 \mathrm{~A}$ & $100,00 \mathrm{~A}$ \\
\hline IPA $467-4-2$ & $62.300 \mathrm{~A}$ & $15.200 \mathrm{~A}$ & $3,08 \mathrm{~B}$ & $70,33 \mathrm{~A}$ & $100,00 \mathrm{~A}$ \\
\hline 46-Сa84-BCa87-B2SB88-BCa89 & $58.100 \mathrm{~A}$ & $18.000 \mathrm{~A}$ & $3,83 \mathrm{~A}$ & $78,00 \mathrm{~A}$ & $96,30 \mathrm{~A}$ \\
\hline 41-Сa84-BCa87-B2SB88-BCa89 & $56.067 \mathrm{~A}$ & $20.267 \mathrm{~A}$ & $3,62 \mathrm{~A}$ & $79,00 \mathrm{~A}$ & $93,53 \mathrm{~A}$ \\
\hline T6 (467-4-2 R1) & $55.800 \mathrm{~A}$ & $15.733 \mathrm{~A}$ & $3,04 \mathrm{~B}$ & $61,00 \mathrm{~B}$ & $96,30 \mathrm{~A}$ \\
\hline 25-Сa84-B2Ca87-B1SB88-BCa89 & $53.667 \mathrm{~A}$ & $19.200 \mathrm{~A}$ & $3,40 \mathrm{~B}$ & $72,00 \mathrm{~A}$ & $92,13 \mathrm{~A}$ \\
\hline Forrageiro-chocolate & $51.600 \mathrm{~A}$ & $21.500 \mathrm{~A}$ & $3,20 \mathrm{~B}$ & $73,00 \mathrm{~A}$ & $98,63 \mathrm{~A}$ \\
\hline $\begin{array}{l}\text { ST87-18;ST88-01;ST89-01;ST90-01; } \\
\text { ST91-13;Vit91-B;Ca92-B }\end{array}$ & $51.333 \mathrm{~A}$ & $17.400 \mathrm{~A}$ & $3,51 \mathrm{~A}$ & $74,67 \mathrm{~A}$ & $91,67 \mathrm{~A}$ \\
\hline Forrageiro-vermelho & $48.900 \mathrm{~A}$ & $14.600 \mathrm{~A}$ & $3,22 \mathrm{~B}$ & $64,67 \mathrm{~B}$ & $99,07 \mathrm{~A}$ \\
\hline Forrageiro-tese-33 & $48.733 \mathrm{~A}$ & $8.500 \mathrm{~B}$ & $2,35 \mathrm{C}$ & $67,00 \mathrm{~B}$ & $100,00 \mathrm{~A}$ \\
\hline 68-Ca84-BCa87-01SB88-01SB89 & $48.433 \mathrm{~A}$ & $15.667 \mathrm{~A}$ & $3,17 \mathrm{~B}$ & $68,00 \mathrm{~B}$ & $90,73 \mathrm{~A}$ \\
\hline 52Ca84-BCa87-B1SB88-BCa89 & $48.133 \mathrm{~A}$ & $13.467 \mathrm{~A}$ & $3,62 \mathrm{~A}$ & $74,67 \mathrm{~A}$ & $97,90 \mathrm{~A}$ \\
\hline SF-25 & $47.500 \mathrm{~A}$ & $15.600 \mathrm{~A}$ & $2,94 \mathrm{~B}$ & $70,00 \mathrm{~A}$ & $100,00 \mathrm{~A}$ \\
\hline 41Ca84-bcA87-B1SB88-BCa89 & $47.467 \mathrm{~A}$ & $17.800 \mathrm{~A}$ & $3,27 \mathrm{~B}$ & $82,00 \mathrm{~A}$ & $87,90 \mathrm{~A}$ \\
\hline $43-70-02$ & $46.867 \mathrm{~A}$ & $17.733 \mathrm{~A}$ & $3,72 \mathrm{~A}$ & $73,00 \mathrm{~A}$ & $90,97 \mathrm{~A}$ \\
\hline 18-Ca84-B1Ca87-SB88B-Ca89 & $46.100 \mathrm{~A}$ & $18.067 \mathrm{~A}$ & $3,68 \mathrm{~A}$ & $75,00 \mathrm{~A}$ & $92,40 \mathrm{~A}$ \\
\hline 25Ca84-B2Ca87-B2SB88-BCa89 & $45.333 \mathrm{~A}$ & $15.267 \mathrm{~A}$ & $3,63 \mathrm{~A}$ & $77,00 \mathrm{~A}$ & $73,60 \mathrm{~A}$ \\
\hline 24Ca84-B1Ca87-B2SB88-BCa89 & $44.067 \mathrm{~B}$ & $17.333 \mathrm{~A}$ & $3,53 \mathrm{~A}$ & $76,00 \mathrm{~A}$ & $86,10 \mathrm{~A}$ \\
\hline 63Сa84-B1Ca87-B2SB88-BCa89 & $42.833 \mathrm{~B}$ & $20.633 \mathrm{~A}$ & $3,75 \mathrm{~A}$ & $74,00 \mathrm{~A}$ & $94,93 \mathrm{~A}$ \\
\hline 25Ca84-B1Ca87-B1SB88-BCa89 & $42.233 B$ & $14.800 \mathrm{~A}$ & $3,57 \mathrm{~A}$ & $78,33 \mathrm{~A}$ & $88,67 \mathrm{~A}$ \\
\hline 41-Ca84-BCa87-B1SB88-BCa89 & $41.833 \mathrm{~B}$ & $16.100 \mathrm{~A}$ & $3,54 \mathrm{~A}$ & $76,00 \mathrm{~A}$ & $87,97 \mathrm{~A}$ \\
\hline 10-Сa84-B2SB88-ВСа89 & $40.500 \mathrm{~B}$ & $15.467 \mathrm{~A}$ & $3,83 \mathrm{~A}$ & $50,67 \mathrm{~B}$ & $86,33 \mathrm{~A}$ \\
\hline BRS Ponta-Negra & $40.367 \mathrm{~B}$ & $11.200 \mathrm{~B}$ & $2,18 \mathrm{C}$ & $61,00 \mathrm{~B}$ & $62,03 \mathrm{~B}$ \\
\hline Forrageiro-tese-25 & $39.867 \mathrm{~B}$ & $12.000 \mathrm{~B}$ & $2,07 \mathrm{C}$ & $83,33 \mathrm{~A}$ & $95,13 \mathrm{~A}$ \\
\hline 10-Ca84-B1Ca87-B1SB88-Ca89 & 39.133B & $14.233 \mathrm{~A}$ & $3,23 \mathrm{~B}$ & $82,33 \mathrm{~A}$ & $89,80 \mathrm{~A}$ \\
\hline T 34 (SUDAN 4202 R1) & $31.333 \mathrm{C}$ & $8.333 \mathrm{~B}$ & $1,96 \mathrm{C}$ & $83,33 \mathrm{~A}$ & $100,00 \mathrm{~A}$ \\
\hline 38-Сa84-B2Сa87-B2SB88-BCa89 & $27.967 \mathrm{C}$ & $9.900 \mathrm{~B}$ & $3,45 \mathrm{~A}$ & $74,00 \mathrm{~A}$ & $93,30 \mathrm{~A}$ \\
\hline IPA $10-11$ & $15.400 \mathrm{C}$ & $4.500 \mathrm{~B}$ & $1,33 \mathrm{D}$ & $83,33 \mathrm{~A}$ & $30,57 \mathrm{C}$ \\
\hline Média & 46.777 & 15.703 & 3,20 & 73,48 & 90,09 \\
\hline
\end{tabular}

Médias seguidas de mesma letra, na coluna, não diferem significativamente entre si a $\mathrm{P}<0,05$ pelo teste Scott-Knott. 
produtivos (média entre 13.467 e $26.100 \mathrm{~kg} / \mathrm{ha}$ ), enquanto outros seis tiveram desempenho inferior (média entre 4.500 e $12.000 \mathrm{~kg} / \mathrm{ha}$ ). O genótipo 02-03-01 apresentou a maior produção média (26.100 kg/ha) e o IPA 10-11 a menor (média de $4.500 \mathrm{~kg} / \mathrm{ha}$ ). Tabosa et al. (2002) registraram, em condições de estresse hídrico, produção média de matéria seca variando de 3.320 a $15.860 \mathrm{~kg} / \mathrm{ha}$ para 02-03-01 e de 2.820 a $20.130 \mathrm{~kg} / \mathrm{ha}$ para SF-25, cultivados em cinco localidades diferentes de Pernambuco. Silva et al. (2005b) constataram rendimento variando de 9.423 a $13.426 \mathrm{~kg} / \mathrm{ha}$ para a matéria seca e Oliveira et al. (2005), rendimento entre 14.220 e $16.380 \mathrm{~kg} / \mathrm{ha}$, com média (15.170 kg/ha) próxima a deste estudo. Para SF-25 e IPA 467-4-2, Aguiar et al. (2006) relataram produção média de matéria seca de 12.169 e $11.868 \mathrm{~kg} / \mathrm{ha}$, respectivamente, enquanto neste estudo esses genótipos tiveram maiores produções.

A altura média da planta foi de 3,20 m e os genótipos de médias semelhantes foram reunidos em quatro grupos distintos: 14 genótipos apresentaram altura média de 3,45 a 3,83 $\mathrm{m}$ e foram considerados os mais altos. Entre eles, destacaram-se 80Ca84-01Ca87-B1SB88-BCa89; 46-Ca84B2Ca87-B2SB88-BCa89 e 10-Ca84-B2SB88-BCa89, com 3,83 m; dez genótipos tiveram média de altura de 2,94 a 3,40 m; quatro genótipos média de 1,96 a 2,35 m; e o IPA 10-11 com 1,33 m apresentou o menor porte. Tabosa et al. (2002) observaram altura da planta variando de 1,08 a 2,98 m para 02-03-01 e de 0,98 a 3,54 m para SF-25. Segundo esses autores, em condições de regularidade climática, a altura média do sorgo pode atingir 3,0 a 4,0 m. Oliveira et al. (2005) obtiveram altura da planta entre 2,12 e 2,74 m (média de 2,39 m) e Neumann et al. (2002b) observaram altura superior para os híbridos forrageiros AG-2002 (2,59 m) e AGX-213 (2,33 m) em comparação aos híbridos de duplo propósito AGX-217 (1,89 m) e AG-2005E (1,72 m), plantados no Rio Grande do Sul. Isto determinou o potencial produtivo de matéria verde (39.563 e $33.454 \mathrm{~kg} / \mathrm{ha}$ de AG-2002 e AGX213 contra 25.375 e $22.707 \mathrm{~kg} /$ ha de AGX-217 e AG-2005E, respectivamente) e matéria seca (10.438 e 9.616 contra 8.610 e $8.153 \mathrm{~kg} / \mathrm{ha}$ ) por unidade de área. Na Índia, Audilakshmi et al. (1999) descreveram altura média da planta de 2,01 m $\left(\mathrm{CV}_{\mathrm{E}}=8 \%\right)$ para 22 genótipos de sorgo. $\mathrm{Na}$
África, Ayana \& Bekele (2000) registraram média de altura de 2,66 $\mathrm{m}\left(\mathrm{CV}_{\mathrm{E}}=40,66 \%\right)$ para 415 genótipos de sorgo e Kenga et al. (2006), média de 2,28 $\mathrm{m}\left(\mathrm{CV}_{\mathrm{E}}=11,71 \%\right)$ para 75 híbridos de sorgo.

Em termos de dias para a floração inicial (média de 73,48 dias), foram reunidos 23 genótipos com número médio de 70 a 83,33 dias, classificados como materiais tardios, ao passo que o grupo dos materiais precoces agregou seis genótipos com médias de 50,67 a 68 dias. Dos genótipos tardios, tiveram destaque Forrageirotese-25; T 34 (SUDAN 4202 R1) e IPA 10-11, todos com média máxima (83,33 dias). O genótipo mais precoce foi o 10-Ca84-B2SB88-BCa89 (50,67 dias). Média inferior (63 dias; $\mathrm{CV}_{\mathrm{E}}=3 \%$ ) à deste estudo foi descrita por Audilakshmi et al. (1999), enquanto Kenga et al. (2006) obtiveram média semelhante (73,7 dias; $\left.\mathrm{CV}_{\mathrm{E}}=4,6 \%\right)$ e Ayana \& Bekele (2000), média superior (115,77 dias; $\mathrm{CV}_{\mathrm{E}}=30,59 \%$ ).

A sobrevivência média foi de $90,1 \%$ e foi mais baixa (30,57\%) no IPA $10-11$, seguido pelo genótipo BRS Ponta-Negra (62,03\%), de percentual mediano. Os demais 27 genótipos apresentaram média semelhante, que variou de 73,60 a $100 \%$, com maiores valores para 02-03-01; IPA 467-4-2; Forrageiro-tese-33; SF-25 e T 34 (SUDAN 4202 R1), que tiveram percentual máximo (100\%) de sobrevivência.

Existe variabilidade genética (variância genotípica, $\mathrm{CV}_{\mathrm{G}}$, $\mathrm{h}^{2}$, t e $\mathrm{I}_{\mathrm{b}}$ não-nulos) entre os genótipos para todas as características (Tabela 2). As estimativas de herdabilidade foram de magnitude moderada a alta e muito alta para a altura da planta (97,05\%). Kenga et al. (2006) obtiveram estimativas de herdabilidade entre 5 e $77 \%$ em diversas características, como altura da planta (77\%) e número de dias para o florescimento (42\%), cujos percentuais foram menores que os deste estudo.

A correlação intraclasse, que traduz a reprodutibilidade do desempenho dos genótipos nos blocos, apresentou magnitude mediana e inferior à da herdabilidade de cada característica, com variação entre 54 e 70\% do seu valor, exceto para a altura da planta, em que foi ligeiramente inferior $(5,6 \%)$ e classificada, portanto, como de alta magnitude.

Tabela 2 - Variância genotípica, coeficiente de variação genético $\left(\mathrm{CV}_{\mathrm{G}}\right)$; herdabilidade $\left(\mathrm{h}^{2}\right)$, correlação intraclasse $(\mathrm{t})$ e índice b $\left(\mathrm{I}_{\mathrm{b}}\right)$ para as características avaliadas

\begin{tabular}{|c|c|c|c|c|c|}
\hline Característica & Variância genotípica & $\mathrm{CV}_{\mathrm{G}}(\%)$ & $h^{2}(\%)$ & t $(\%)$ & $\mathrm{I}_{\mathrm{b}}$ \\
\hline Matéria verde & $88.714,43$ & 20,14 & 74,76 & 49,68 & 0,99 \\
\hline Matéria seca & $13.872,18$ & 23,72 & 69,46 & 43,12 & 0,87 \\
\hline Altura da planta & 0,39 & 19,56 & 97,05 & 91,64 & 3,31 \\
\hline Floração inicial & 32,36 & 7,74 & 58,21 & 31,71 & 0,68 \\
\hline Sobrevivência & 156,95 & 13,91 & 79,11 & 55,80 & 1,12 \\
\hline
\end{tabular}


O índice b $\left(\mathrm{I}_{\mathrm{b}}\right)$, razão entre os coeficientes de variação genético e experimental, teve o menor resultado para a floração inicial $(0,68)$ e o maior para a altura da planta (3,31). Esse índice ajuda a detectar variabilidade genética na população, independentemente da média da característica, e quando resulta em valor igual ou maior que 1,0 , indica que a situação é favorável para a seleção genética (Mistro et al., 2007; Souza et al., 2007).

A matéria verde (Tabela 3) apresentou correlação genotípica positiva e de magnitude elevada (maior que 0,70 ) com a matéria seca $(0,83)$ e com a sobrevivência $(0,71)$ e mediana $(0,40-0,70)$ com a altura da planta $(0,61)$. As correlações fenotípicas correspondentes foram de mesmo sinal e ligeiramente inferiores (0,76; 0,61 e 0,52) às genotípicas, o que reflete maior contribuição dos fatores genéticos em relação aos ambientais para a expressão destas características. Comportamento semelhante foi descrito por Kenga et al. (2006) entre alguns pares das características.

As correlações genotípica $(-0,31)$ e fenotípica $(-0,21)$ negativas e baixas, embora significativas, da matéria verde com a floração inicial, sugerem fraca associação linear entre elas. Entre matéria seca e altura da planta, foram verificadas correlações genotípica e fenotípica altas e positivas, isto é, da ordem de 0,87 e 0,72, respectivamente. Mulcahy et al. (1992) descreveram correlações fenotípicas de 0,85 e 0,75 $(\mathrm{P}<0,05)$ entre matéria seca e altura da planta nos anos de 1988 e 1989, respectivamente, para híbridos e cultivares de sorgo forrageiro no total de 11 materiais. Tomich et al. (2004) afirmaram que a altura da planta de sorgo é importante por ser uma característica que normalmente se associa às características produtivas. Esses autores avaliaram 25 híbridos de sorgo com capim-sudão plantados em Sete Lagoas, Minas Gerais, no mês de outubro de 2002 e observaram correlações fenotípicas significativas $(\mathrm{P}<0,01)$, porém inferiores às deste estudo, entre altura da planta e as produções de matéria verde $(0,47)$ e matéria seca $(0,55)$, como também correlação negativa e indesejável $(-0,33)$ entre altura da planta e relação folha/colmo, o que sugere cautela na escolha da altura como critério de seleção daqueles genótipos.
As correlações foram positivas e de magnitude mediana entre matéria seca e sobrevivência: a genotípica, de 0,56 e a fenotípica, de 0,47. Correlações de magnitude semelhante também foram observadas entre altura da planta e sobrevivência (0,51 e 0,47, naquela ordem).

Cruz et al. (2004) atribuíram como causa principal da correlação genética a pleiotropia, de modo que, se dois caracteres apresentam correlação genética favorável, é possível obter ganhos para um deles por meio da seleção indireta no outro associado. Segundo esses autores, em alguns casos, a seleção indireta, com base na resposta correlacionada, pode levar a progressos mais rápidos que a seleção direta da característica desejada.

De acordo com Silva et al. (2005a), maiores alturas da planta de sorgo são atribuídas aos efeitos de fotoperíodos não-indutivos (maiores que 12,9h) da diferenciação floração durante a fase vegetativa dos cultivares, proporcionando formação de maior número de nós, entrenós e de primórdios foliares com emissão de maior número de folhas, o que resulta em aumento da produção de matéria verde e de matéria seca. Por outro lado, as plantas de menor estatura apresentam menor porcentagem de colmos na matéria seca, o que implica melhor qualidade da forragem (Chaves, 1997).

Das características avaliadas, a floração inicial foi a que se mostrou menos correlacionada às outras, quer pela baixa magnitude dos coeficientes de correlação quer pela sua não-significância no teste $t$, o que sugere pouca sensibilidade dos genótipos avaliados a fotoperíodos indutivos do florescimento na região. Audilakshmi et al. (1999) também não constataram correlação significativa entre número de dias para floração e cada uma das características que avaliaram.

Todas as correlações entre floração inicial e as demais características foram negativas, confirmando resultados de Kenga et al. (2006), que obtiveram, sobretudo, correlações genotípicas negativas, mas significativas $(\mathrm{P}<0,01)$, entre esta característica e altura da planta $(-0,29)$ e comprimento da inflorescência $(-0,19)$ e massa da semente $(-0,28)$. Esses autores verificaram que a floração precoce foi mais fortemente correlacionada com a estatura baixa da planta, inflorescência curta e semente leve, de modo que selecionar

Tabela 3 - Correlações genotípicas e fenotípicas (acima e abaixo da diagonal principal) entre as características de sorgo

\begin{tabular}{lccccc}
\hline & Matéria verde & Matéria seca & Altura da planta & Floração inicial & Sobrevivência \\
\hline Matéria verde & 1,00 & $0,83^{*}$ & $0,61^{*}$ & $-0,31^{*}$ & $0,71^{*}$ \\
Matéria seca & $0,76^{*}$ & 1,00 & $0,87^{*}$ & $-0,18^{\mathrm{ns}}$ & $0,56^{*}$ \\
Altura da planta & $0,52^{*}$ & $0,72^{*}$ & 1,00 & $-0,20^{\mathrm{ns}}$ & $0,51^{*}$ \\
Floração inicial & $-0,21^{*}$ & $-0,05^{\mathrm{ns}}$ & $-0,16^{\mathrm{ns}}$ & 1,00 & $-0,27^{*}$ \\
Sobrevivência & $0,61^{*}$ & $0,47^{*}$ & $0,47^{*}$ & $-0,11^{\mathrm{ns}}$ & 1,00 \\
\hline
\end{tabular}

*: Significativa a $\mathrm{P}<0,05$ pelo teste t; ns: Não-significativa. 
para precocidade de floração deveria reduzir as características vegetativas. Diferentemente, Audilakshmi et al. (1999) e Ayana \& Bekele (2000) estimaram correlação fenotípica positiva entre dias para floração e altura da planta (0,38 e 0,65, respectivamente).

\section{Conclusões}

Como há alta variabilidade genética entre os genótipos para a maioria das características, é possível obter ganho genético por seleção direta. A altura da planta pode ser utilizada como critério de seleção para melhoria indireta da produção de matérias verde e seca. A floração inicial associa-se fracamente com as demais características.

\section{Agradecimentos}

Ao Banco do Nordeste do Brasil S.A., pelo suporte financeiro, e à EMPARN e UFRN, pela infraestrutura.

\section{Referências}

AGUIAR, E.M.; LIMA, G.F.C.; SANTOS, M.V.F. et al. Rendimento e composição químico-bromatológica de fenos triturados de gramíneas tropicais. Revista Brasileira de Zootecnia, v.35, n.6, p.2226-2233, 2006.

AUDILAKSHMI, S.; STENHOUSE, J.W.; REDDY, T.P. et al. Grain mould resistance and associated characters of sorghum genotypes. Euphytica, v.107, p.91-103, 1999.

AYANA, A.; BEKELE, E. Geographical patterns of morphological variation in sorghum (Sorghum bicolor (L.) Moench) germoplasm from Ethiopia and Eritrea: quantitative characters. Euphytica, v.115, p.91-104, 2000.

CHAVES, A.V. Avaliação de cultivares de sorgo (Sorghum bicolor L. Moench) para produção de silagem. 1997. $35 \mathrm{f}$. Dissertação (Mestrado em Fitotecnia) - Universidade Federal de Viçosa, Viçosa, MG.

CRUZ, C.D. Programa Genes: versão Windows; Aplicativo computacional em genética e estatística. Viçosa, MG: Editora UFV, 2001. 648p.

CRUZ, C.D.; REGAZZI, A.J.; CARNEIRO, P.C.S. Modelos biométricos aplicados ao melhoramento genético. V.1. 3.ed. Viçosa, MG: Editora UFV, 2004. 480p.

IGARASI, M.S.; ARRIGONI, M.B.; SOUZA, A.A. et al. Desempenho de bovinos jovens alimentados com dieta contendo grão úmido de milho ou sorgo. Revista Brasileira de Zootecnia, v.37, n.3, p.513-519, 2008.

KENGA, R.; TENKOUANO, A.; GUPTA, S.C. et al. Genetic and phenotypic association between yield components in hybrid sorghum (Sorghum bicolor (L.) Moench) populations. Euphytica, v.150, p.319-326, 2006.

LIMA, J.M.P. Recomendações técnicas para o cultivo do sorgo no Rio Grande do Norte. EMPARN. Natal, RN. 1993. 5p. (Recomendações Técnicas).

MARIGUELE, K.H.; SILVA, P.S.L. Avaliação dos rendimentos de grãos e forragem de cultivares de sorgo granífero. Caatinga, v.15, p.13-18, 2002.

MISTRO, J.C.; FAZUOLI, L.C.; GALLO, P.B. et al. Estimates of genetic parameters in Arabic coffee derived from the Timor hybrid. Crop Breeding and Applied Biotechnology, v.7, p.141-147, 2007.

MULCAHY, C.; HEDGES, D.A.; RAPP, G.G. et al. Correlations among potential selection criteria for improving the feeding value of forage sorghums. Tropical Grasslands, v.26, p.7-11, 1992.

NASCIMENTO, W.G.; PRADO, I.N.; JOBIM, C.C. et al. Valor alimentício das silagens de milho e de sorgo e sua influência no desempenho de vacas leiteiras. Revista Brasileira de Zootecnia, v.37, n.5, p.896-904, 2008.

NEUMANN, M.; RESTLE, J.; ALVES FILHO, D.C. et al. Avaliação de diferentes híbridos de sorgo (Sorghum bicolor, L. Moench) quanto aos componentes da planta e silagens produzidas. Revista Brasileira de Zootecnia, v.31, n.1, p.302-312, 2002a.

NEUMANN, M.; RESTLE, J.; ALVES FILHO, D.C. et al. Avaliação do valor nutritivo da planta e da silagem de diferentes híbridos de sorgo (Sorghum bicolor, L. Moench). Revista Brasileira de Zootecnia, v.31, n.1, p.293-301, 2002b.

OLIVEIRA, J.S.; FERREIRA, R.P.; CRUZ, C.D. et al. Adaptabilidade e estabilidade em cultivares de sorgo. Revista Brasileira de Zootecnia, v.31, n.2, p.883-889, 2002.

OLIVEIRA, R.P.; FRANÇA, A.F.S.; RODRIGUES FILHO, O. et al. Características agronômicas de cultivares de sorgo (Sorghum bicolor (L.) Moench) sob três doses de nitrogênio. Pesquisa Agropecuária Tropical, v.35, n.1, p.45-53, 2005.

PITOMBEIRA, J.B.; CASTRO, A.B.; POMPEU, R.C.F.F. et al. Adaptabilidade e estabilidade de genótipos de sorgo forrageiro em cinco ambientes do estado do Ceará. Ciência Agronômica, v.34, n.1, p.20-24, 2002.

SILVA, A.G.; ROCHA, V.S.; CECON, P.R. et al. Avaliação dos caracteres agronômicos de cultivares de sorgo forrageiro sob diferentes condições termo-fotoperiódicas. Revista Brasileira de Milho e Sorgo, v.4, n.1, p.28-44, 2005a.

SILVA, A.G.; ROCHA, V.S.; CRUZ, C.D. et al. Adaptabilidade e estabilidade de cultivares de sorgo forrageiro semeados em diferentes épocas do ano. Revista Brasileira de Milho e Sorgo, v.4, n.1, p.112-125, 2005 b.

SOUZA, C.L.C.; LOPES, A.C.A.; GOMES, R.L.F. et al. Variability and correlations in cowpea populations for green-grain production. Crop Breeding and Applied Biotechnology, v.7, p.262-269, 2007.

TABOSA, J.N.; REIS, O.V.; BRITO, A.R.M.B. et al. Comportamento de cultivares de sorgo forrageiro em diferentes ambientes agroecológicos dos Estados de Pernambuco e Alagoas. Revista Brasileira de Milho e Sorgo, v.1, n.2, p.47-58, 2002.

TOMICH, T.R.; RODRIGUES, J.A.S.; TOMICH, R.G.P. et al. Potencial forrageiro de híbridos de sorgo com capim-sudão. Arquivo Brasileiro de Medicina Veterinária e Zootecnia, v.56, n.2, p.258-263, 2004. 